
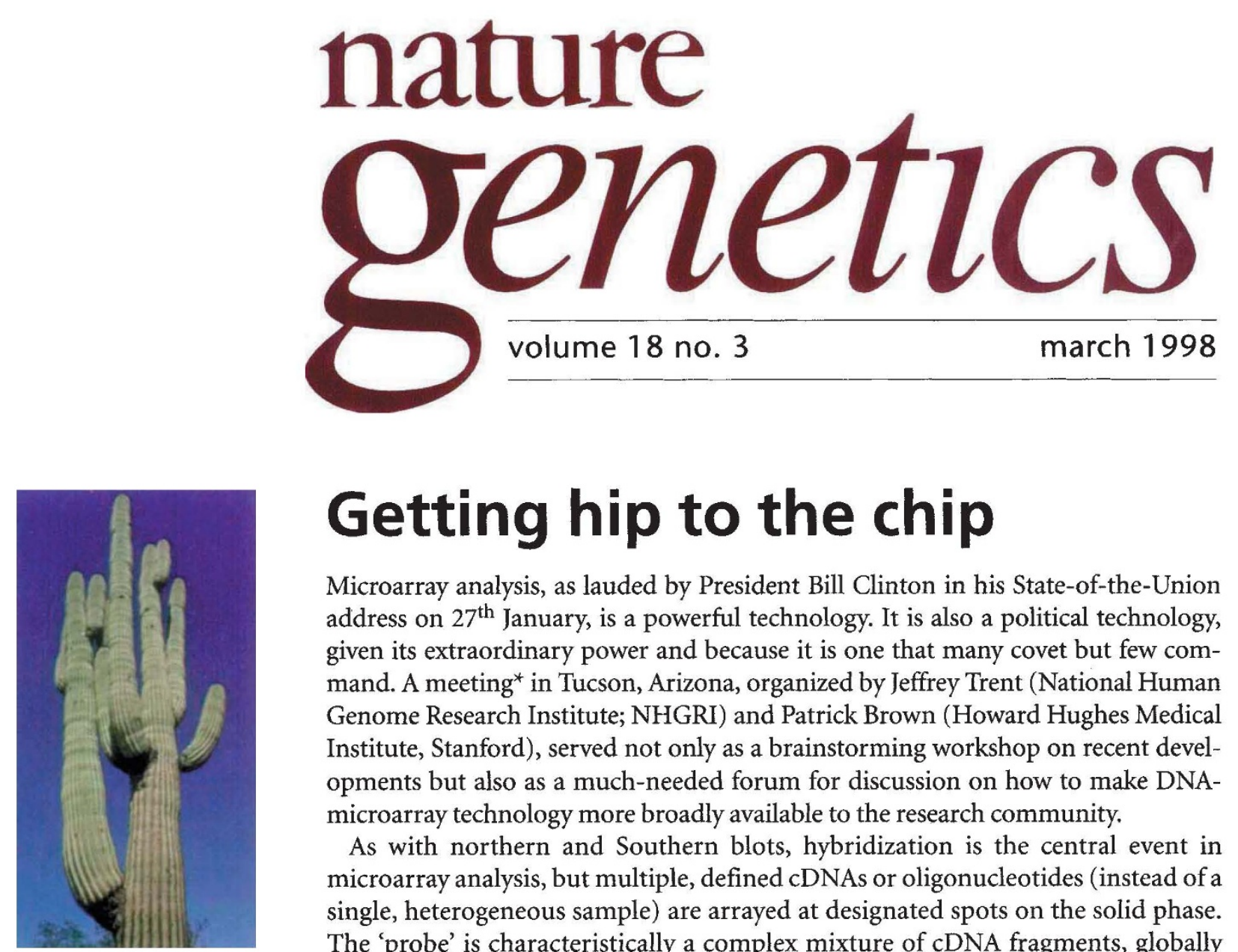

\title{
Getting hip to the chip
}

Microarray analysis, as lauded by President Bill Clinton in his State-of-the-Union address on $27^{\text {th }}$ January, is a powerful technology. It is also a political technology, given its extraordinary power and because it is one that many covet but few command. A meeting* in Tucson, Arizona, organized by Jeffrey Trent (National Human Genome Research Institute; NHGRI) and Patrick Brown (Howard Hughes Medical Institute, Stanford), served not only as a brainstorming workshop on recent developments but also as a much-needed forum for discussion on how to make DNAmicroarray technology more broadly available to the research community.

As with northern and Southern blots, hybridization is the central event in microarray analysis, but multiple, defined cDNAs or oligonucleotides (instead of a single, heterogeneous sample) are arrayed at designated spots on the solid phase. The 'probe' is characteristically a complex mixture of cDNA fragments, globally generated from mRNA, although genomic DNA fragments are sometimes used. The theoretical power of the technology lies in being able to monitor 'global' gene expression. On comparing it with more traditional methods of analysis, one participant suggested that it was like "turning on a light after trying to discern the details of one's surroundings with a torch" (see page 200; refs 1,2 ).

The diverse range of biological questions addressed by microarray analyses is reminiscent of Saguaro cacti, in which a profusion of arms sometimes branch from a central locus. Joe de Risi (Stanford) who used an arrayer built in Patrick Brown's lab, provided a lucid example of how array analysis can implicate new players in old processes (in this case, the metabolic reprogramming that occurs during the diauxic shift in yeast ${ }^{3}$ ) and Ron Davis (Stanford) explained how, by 'bar-coding' yeast, one can genotype thousands of mutants in a single hybridization ${ }^{4}$. These presentations were notable for the way in which they charted dynamic gene expression and exploited the obvious advantages of using an organism that is easily manipulated and well-characterized, most notably in the genomic sense. One of the most original applications of array technology was described by Vishy Iyer, also of the Stanford contingent. In collaboration with others, he hopes to identify motifs in intragenic regions to which transcription factors (or chromatin-modifiers) bind, by crosslinking proteins with DNA, immunoprecipitating the 'bound' protein of interest, dissociating DNA from protein, and then using the DNA to probe an array of intragenic elements. This approach is, at present, possible only with yeast, in which the intragenic regions are sequenced and are of a manageable size.

Humans, of course, are not as malleable as yeast; many of the presentations regarding human biology were necessarily 'comparisons' in which gene expression 


\section{IMAGE \\ UNAVAILABLE FOR COPYRIGHT REASONS}

Fig. I Visual display of large sets of gene expression data. Genes are clustered according to the similarity of their expression profiles across a number of experiments. Each row represents a gene and each column represents a different experimental condition-in this example, 11 time-points during the growth stimulation of cells (the four columns on the right represent the first four time-points in the presence of cycloheximide). For each experimental observation, genes that are induced are represented by red boxes and genes that are turned down are represented by green boxes. The intensity of the colour is proportional to the magnitude of the relative change in expression, allowing one to rapidly scan for genes with specific expression profiles and for sets of genes with similar behavior. Image kindly supplied by Mike Eisen and Vishy lyer. characterizing one phenotype (for example, a tumour sample) was compared with that of another (usually a control sample). While these results often included a predictable change in the expression of known genes, which is reassuring, the poster of Sally Amundson and colleagues (NHGRI) addressed the issue of validation by comparing data obtained using microarrays and quantitative hybridization. Happily, they found a good correlation between expression levels detected by both methods.

Only a fraction of human genes are represented by publicly-available, sequencevalidated cDNA clones, and arrays yield expression data that are proportional to the number of genes represented upon them. The opportunity to simultaneously monitor the activity of every human gene has added to the urgency and intensity of efforts to obtain a catalogue of human CDNAs representing the entire repertoire of human gene products. The hunger for more CDNAs was the focus of repeated reference, perhaps not entirely unconnected with a recent decision by the Cancer Genome Anatomy Project ${ }^{5,6}$ to support an effort to obtain full-length sequences of clones in the Unigene set (a set of cDNA clones that is publicaly available) by the beginning of 1999. According to Harold Varmus, director of the NIH, the Institutes are interested in supporting technological development and in two sequencing endeavours: (i) to obtain reliable Unigene sets for both the mouse and the human and (ii) to obtain full-length human coding sequence. The impending availability of additional CDNA clones will intensify what most participants perceived to be perhaps the greatest challenge facing the field- "the development of efficient methods and standards for organizing, distributing and interpreting the large volumes of data generated by microarray experiments" 3 .

Although the visual image of a microarray panel is alluring, its information content, per se, is minimal without significant image processing. To mine its lode effectively, quantitative signal must be determined optimally, which means subtracting background, calculating confidence intervals-outside of which a difference in signal ratio is deemed to be significant-and calibrated. A program featuring these basic image-processing mechanics, the DeArray program, was described by Yidong Chen and Mike Bittner (NHGRI), and will soon be made available to academic researchers on request. Quantitation of expression as monitored by cDNA/poly-lysine chips is affected by a non-linear relationship between signal strength and the amount of probe present, according to Mike Bittner (NHGRI) and Mike Eisen (Stanford), resulting in an underestimate of the extent of large changes in expression, especially between abundant species of mRNA. The lower end of the expression spectrum is also subject to distortion, which is influenced by the type of probe used-a matter of concern given that subtle changes in genes with low-level expression are as likely to be important (with respect to determining phenotype) as more dramatic differences.

How can one visualize, organize and explore the meaning of information consisting of several million measurements of expression of thousands of genes under thousands of conditions? Mike Eisen and Edward Dougherty (Texas A\&M University) presented algorithms that permit the clustering of genes with similar patterns of expression over different time points (Figs 1,2), thereby allowing one to fit every gene for which there is expression data generated into a temporal framework that allows a gene-to-gene comparison. Software systems for managing and analysing data were presented by Mark Boguski and Olga Ermolaeva (of the National Center for Biotechnology Information; NCBI) and Deval Lashkari (of Synteni; software will be commercially available soon). The Internet is the only vehicle capable of handling data of the scale generated by microarray analysis; how best to organize a 


\begin{tabular}{|c|c|}
\hline Affymetrix & $\begin{array}{l}\text { market human chip with elements representing } 40,000 \text { genes, 'custom' arrays - for example, mapping-arrays for } \\
\text { linkage analysis and arrays sporting SNP variants in different drug-metabolism pathways }\end{array}$ \\
\hline Genome Systems & market more filter arrays and sequence-validated clone sets; develop mouse, 'custom' and glass arrays \\
\hline Genetic MicroSystems & market arrayer ( $\sim \$ 30 \mathrm{k})$; instruments to be tested by collaborators in Spring, ' 98 \\
\hline Hewlett-Packard & ink-jet arrays under development \\
\hline Jeffrey Trent & $\begin{array}{l}\text { make available NHGRI-supported webpage detailing new protocols, instrumentation and software available in } \\
\text { '98; verify set of sequenced clones to be used as community standards; support efforts to have } 3 \text { 'ends of mouse } \\
\text { clones sequenced }\end{array}$ \\
\hline Molecular Dynamics & continue access program; start selling arrayers and scanners (cost for complete system up to $\$ 250 \mathrm{k}$ ) \\
\hline NCBI & provide repository for genome-scale expression data \\
\hline $\mathrm{NIH} / \mathrm{NCI} / \mathrm{NHGRI}$ & $\begin{array}{l}\text { provide sequence-validated human cDNA sets by full-length cDNA sequencing, support technology development } \\
\text { and dissemination, explore development of a common internal standard to allow comparison between } \\
\text { experiments }\end{array}$ \\
\hline Patrick Brown & $\begin{array}{l}\text { distribute over the internet details on assembly, instrumentation and protocols to help build arrayers }(\sim 20 \mathrm{k}) \text { and } \\
\text { scanners }(\sim 30 \mathrm{k}) \text {; produce and use } 1000 \text { yeast-genome arrays and human cDNA arrays with } 10,000 \text { genes on each } \\
\text { array; develop new analysis tools }\end{array}$ \\
\hline Research Genetics & $\begin{array}{l}\text { re-sequence (validate) } 40,000 \text { clones by ' } 99 \text {; individual clones to sell at } \$ 24 / \text { clone; provide membrane arrays } \\
\text { ( } \$ 900 @ ; \text {; reusable 5-6x) and software for array analysis, available imminently }\end{array}$ \\
\hline Synteni/Incyte & $\begin{array}{l}\text { implement access program, start selling scanners }(\sim 50 \mathrm{k}) \text {, provide service for hybridizing and scanning; imminent } \\
\text { sale of four-chip arrays with total of } 40 \mathrm{k} \text { genes represented between the four }\end{array}$ \\
\hline
\end{tabular}

For details on current products and services, see refs 9, 10.

1. Kruglyak, L. \& MCAllister, L. Nature Genet. 18 200-203 (1998).

2. Brown, P.O. \& Hartwell, L. Nature Genet. 18 91-93 (1998).

3. DeRisi, J.L., lyer, V.R. \& Brown, P.O. Science 278 680-686 (1997).

4. Lashkari, D.A. et al. PNAS USA 94, 13057-13062 (1997).

5. Strausberg, R.L., Dahl, C.A. \& Klausner, R.D. Nature Genet. 15, 415-416 (1997).

6. http://inhouse.ncbi.n/m.nih.gov/ncicgap/

7. http://Www.nhgri.nih.gov/DIR/LG/15K/inks.htm

8. http://cmgm.stanford.edu/pbrown/array.htm

. Marshall, A. \& Hodgson, J. Nature Biotech. 16. 27-32 (1998).

10. Castellino, A.M. Genome Res. 7, 943-946 (1997). depository for data is currently under discussion at the NCBI. As a consequence of the Tucson meeting, a webpage ${ }^{7}$ has been created with annotated links to both academic and corporate array-related sites.

A spirited discussion featured eloquent argument by David Botstein (Stanford), who advocated that people roll up their sleeves and get intimate with nuts and bolts by building their own equipment. Many people and institutes are pondering how best to invest funds; a vulnerable move when the technology is changing kaleidoscopically and chip companies are suing each other left, right and centre. Technophobia undoubtedly contributes to a leeriness of the do-it-yourself (DIY) approach, and those who have built their own arrayers do not profess it to be easy; some (but not all) have relied on professional engineers for assistance. DIY projects have, however, always been tough for the first to attempt them, and those who have been successful in constructing their own arrayers are keen to share their experience ${ }^{8}$. The fact that the arrayer used by Vivian Cheung (U. Penn.) to map the congenital hyperinsulinaemia gene (see pages 200 and 225) was put together in four months is an encouraging example. It is also likely that 'the technology' will not only become more affordable but the number of different variants (or options) will continue to increase ${ }^{9,10}$, as illustrated by two-year predictions provided by representatives of groups/companies at the meeting (see table).

Despite the mouth-watering potential that many people associate with chip technology, its limitations and points of reference are not clear. Basic questions have yet to be answered, such as how to measure small changes of gene expression accurately when approximately $85 \%$ of RNA transcripts are of low abundance; how to determine suitable standards with which to compare results between experiments (the need for this was highlighted by Francis Collins, NHGRI); how to maximally exploit and share data; how to organize resources most effectively; how to 'track' huge numbers of clones; how to integrate the technology with clinical trials (the importance of which was underscored by Sydney Salmon, U. Arizona). Whether "gene chips will offer a road map for prevention of illness throughout a lifetime", as President Clinton boldly predicted in his recent State-of-the-Union speech, will depend on optimal exchange of information between members of the scientific community. 